\title{
Comparison of primary four students' perceptions towards self-directed learning and collaborative learning with technology in their English writing lessons
}

\author{
Doris Choy $^{1,2}$ - Yin Ling Cheung ${ }^{1,2}$
}

Received: 26 August 2021 / Revised: 7 December 2021 / Accepted: 6 January 2022 /

Published online: 15 January 2022

(C) Beijing Normal University 2022

\begin{abstract}
The purpose of this study is to examine Primary school students' perceptions towards self-directed learning (SDL) and Collaborative learning (CL) with and without the integration of Information and Communication Technologies (ICT) in English writing lessons in Singapore. There were 408 students participated in this study voluntarily. The results showed that the participants' perceptions for SDL and CL were positive in both control and ICT-enhanced experimental groups, with means ranged from 3.73 to 3.90 out of a 5-point Likert scale. Both groups' perceptions for SDL with technology and CL with technology were consistent lower than without technology, ranged from 2.98 to 3.72. MANCOVA was used to compare the difference in perceptions between the control and the experimental groups. The results showed that there were significant differences between the two groups in the perceptions of SDL with technology and CL with technology. The experimental group used a variety of technology tools, such as tablets, online writing assistant tools and online notice boards to facilitate their narrative writings during the 5-week intervention. They have opportunities to develop self-direct learning skills through the online writing assistant tool, they practiced collaborative learning skills through sharing their narratives and providing constructive peer feedback on online notice boards. The results indicated that students in the ICT-enhanced experimental group perceived significantly more positive perceptions towards both SDL with technology and CL with technology. As the Covid-19 pandemic continues to sweep across the world, learning activities conducted in this study could be applicable to blended or
\end{abstract}

Doris Choy

doris.choy@nie.edu.sg

1 Learning Sciences and Assessment Academic Group, National Institute of Education, Nanyang Technological University, 1 Nanyang Walk, Singapore 637616, Singapore

2 Office of Graduate Studies and Professional Learning, English Language \& Literature Academic Group, National Institute of Education, Nanyang Technological University, 1 Nanyang Walk, Singapore 637616, Singapore 
online English lessons to facilitate the development of students' Self-directed learning and Collaborative learning skills through the ICT-enhanced learning activities. Some recommendations will be discussed in the paper.

Keywords Twenty-first century skills $\cdot$ Self-directed learning $\cdot$ Collaborative learning $\cdot$ Technology-enhanced learning $\cdot$ Blended learning

\section{Introduction}

The twenty-first century has also been referred to as the Knowledge Age (UNESCO, 2005), with the continuous innovation, dissemination, and creation of new knowledge has become the pillar to advancing economies. In the education landscape, various organizations defined twenty-first century competencies, which are the knowledge and skills that are needed to develop future ready students for the future. Some key principles of learning in 21st Century include: Information processing skills, Technology, Communication and Collaboration skills and competencies (Ministry of Education Singapore, 2021b; Anderson, 2008; Ministry of Education Singapore, 2021a; Voogt \& Pareja Roblin, 2010). Some of these principles could be further unpacked into self-directed learning skills, communication and collaborative learning skills, information literacy skills, technological skills etc. With the recent announcement of the Educational Technology (EdTech) Plan, Ministry of Education in Singapore aims to build on the foundations of the four ICT Masterplans to make prepare future ready digital learners to be: self-directed, connected with the community and the world, and responsible learners when navigating the digital space (Ministry of Education Singapore, 2021a).

The motivated strategies for learning questionnaire (MSLQ), proposed by Pintrich et al. (1991), has been widely used by scholars to examine the relationship between students' motivation and their use of learning strategies (Credé \& Phillips, 2011; Hilpert et al., 2013; Pintrich et al., 1991). However, it is found that the MSLQ is not comprehensive given the increasing prevalence of ICT in education and attention on developing twenty-first century skills. There are also few studies examining the differences in young learners' motivation and their uptake of twenty-first century skills such as self-directed learning and collaborative learning with or without ICT support (Chai et al., 2016).

This study attempted to investigate the perceptions of Primary Four students' self-directed learning and collaborative learning in an ICT-enhanced English writing lessons. Their perceptions were compared with a control group. A 28-item validated survey, Motivated Self-directed learning (SDL) and Collaborative learning (CL) Questionnaire (MSDLCL) was adopted to collect data from the participants (Choy et al., 2016). The findings from this study will be able to contribute to this area of research in various aspects. Firstly, although there has been increasing number of research studies related to self-directed learning, collaborative learning (Genlott \& Grönlund, 2016; Robertson, 2011; Tan et al., 2017), there are few studies examining the differences in young learners' motivation and their uptake of twenty-first century 
skills such as self-directed learning and collaborative learning with technology (Chai et al., 2016). Secondly, most of the studies focused on University level students (Morrison \& McCuthenon, 2019; Sletten, 2017) and only few studies looked at students from K-12 settings in recent years. Thirdly, studies have explored the development of self-directed learning and collaborative learning with technology in mathematics and sciences related subjects (Salonen et al., 2017) and limited studies focus on English Language. To address this research gap, this study conducted a 5-week intervention in three government schools with 408 Primary Four student participants. This study will be able address these gaps in the current literature.

The results of this study showed that all students had slightly positive perceptions towards Self-directed learning (SDL) and Collaborative learning (CL) in their English writing lessons (3.73-3.90). MANCOVA also showed that there were significant differences in the students' perceptions in Self-directed learning with technology (SDLT) and Collaborative learning with technology (CLT) between the control and the ICT-enhanced experimental groups.

\section{Literature review}

\section{Motivated strategies for learning}

Over the last few decades, motivational constructs have been recognized to have positive influence on academic learning. Motivated students are more attentive, display greater progress and higher levels of mastery, learn independently, and experience increased satisfaction and positive affect (Zimmerman \& Schunk, 2008). More motivated strategies such as Self-directed learning (SDL) and Collaborative learning (CL) have thus been widely adopted for academic learning in recent years. In this review, key research studies related to motivated strategies for learning, self-directed learning, collaborative learning with and without the use of technologies, and the relevant validated instruments will be discussed.

\section{Self-directed learning $(S D L)$}

Self-directed learning (SDL has been widely studied in the last few decades (Brockett, 2000), often refers to the learners taking primary initiative, responsibility and control for their learning (Kicken et al., 2009; Morrison \& McCutheon, 2019). It is often defined as "the learner's psychological processes that are purposively and consciously controlled, or directed, for the purpose of gaining knowledge and understanding, solving problems, and developing or strengthening a skill" (Long, 1994, p. 14). In short, learners can learn with curiosity, autonomy, and in a self-controlled manner (Sletten, 2017). Similarly, in Self-regulated Learning (SRL), a related learning strategy, learners have control over their own learning by using a set of learning strategies (Pintrich, 2004; Zimmerman \& Schunk, 2008). For example, to achieve the specific learning goals they proactively set, learners would have direct cognition, use effective strategies, and keep reflecting on their learning (Loyens et al., 2008; Schunk, 2005). Such cognitive, metacognitive, and management SRL strategies 
have been proven to be effective for academic performances (Sahlin et al., 2017). Moreover, Bai (2018) indicated that enhanced motivation could improve SRL as high achievers were found to have higher level of motivation and use more than one SRL strategies. While SDL and SRL are similar in promoting learners to be independent in achieving learning goals, the former is broader as it ascribes more learner agency. As such, SDL is often seen to encompass SRL, but not vice versa (Jossberger et al., 2010; Saks \& Leijen, 2014). While studies have reported that there is a close relationship between SDL and motivation (Morrison \& McCutheon, 2019) and performance (Yang \& Li, 2013), there have been few studies on SDL in the Asia-Pacific region. Yamada et al. (2015) considered the relationship between SRL, procrastination, and learning in a blended learning environment. They found that SRL and procrastination affects learning behaviors positively in first-year Japanese university students. Given the continued proclivity for teacher-directedness in Asia (Leong et al., 2018; Shah \& Quinn, 2016), there is a need to consider how a learnerdirected learning strategy like SDL affects learning in more teacher-directed education systems.

\section{Collaborative learning $(C L)$}

Collaborative Learning (CL) can be broadly defined as "a situation in which two or more people learn or attempt to learn something together" (Dillenbourg, 1999, p. 1). While there is no consensus on a specific definition, Collaborative learning often refers to the learning process of learners creating knowledge, completing shared tasks, developing group outcomes, or achieving shared learning goals together (Barkley et al., 2014). Studies indicated that such learning process could thus encourage learners to engage in conversations with peers such as exchanging opinions, negotiating and sharing perspectives (Lee \& Hannafin, 2016). In Collaborative Learning, learning is a social activity where individuals work on a shared task and co-construct knowledge (Stahl et al., 2014), and has been found to be effective in increasing motivation, encouraging active learning, developing critical thinking, communication, and decision-making skills (Santos et al., 2018). Results from a study conducted by Shih (2021) also showed that CL has positive effect on university students' development of learner autonomy including reflection, self-evaluation, metacognitive knowledge, and emotional intelligence.

\section{Integrated motivated strategies with technology}

Information and Communication Technology (ICT) has been increasingly incorporated in and subsequently changed twenty-first century classrooms (Li \& Zheng, 2018; Wu et al., 2017). The use of ICT tools has become more widespread and familiar among the student populations (Wu et al., 2017), and leveraging ICT has become integral in UNESCO's drive to "strengthen education systems, knowledge systems, knowledge dissemination, information access, quality and effective learning" (UNESCO, 2017). Recent studies have considered perceptions around ICT implementation (Cohen et al., 2017; Salonen et al., 2017; Van de Oudeweetering \& 
Voogt, 2018; Wu et al., 2017), the impact of ICT on learners' motivation (Lawlor et al., 2016; Sahlin et al., 2017; Siddiq et al., 2017), impact of ICT on academic performances (Genlott \& Grönlund, 2016), as well as ICT proficiency and access (Goh $\&$ Kale, 2016). There is increasing recognition that equipping learners to be lifelong learning, and hence a key feature of future-ready citizens (Robertson, 2011).

\section{Self-directed learning with technology (SDLT)}

With the increasing emphasis on the use of ICT in twenty-first century learning, there is greater interest in how ICT can enable and complement the development of Self-directed Learning (SDL) (Callaghan, 2016; Robertson, 2011; Yang \& Li, 2013). Recent studies also suggested that SDL is beneficial for online learning environments as learners with higher motivation level and self-control are more capable to be actively engaged during online learning (Karatas \& Arpaci, 2021). In an experimental study conducted by Trúchly et al. (2019), the impact of using virtual labs and self-tests as part of the SDL approaches was analyzed among secondary and university students in Slovakia. It was found that the experimental group achieved significantly higher knowledge gain. However, there was no increase in interest in the subject, and students continued to prefer teacher-based learning strategies than SDL. Similarly, a study conducted by Hong and Chai (2017) also indicated that college students' procrastination during the online learning was relevant with their perceived learning ineffectiveness with SRL. In addition, Karatas and Arpaci (2021) suggested that it is important for prospective teachers to be equipped with twenty-first century skills including: ICT literacy, self-directed learning skills, and metacognitive awareness to better prepare their learners for the online learning environments.

While there has been many studies discussed the use of SDLT in higher and continuing education in the past decade, there is a growing interest in exploring the development of SDLT in K-12 learners in recent years (Naz \& Hussain, 2020). Yet, the research is still limited to specific ICT platforms. For example, Callaghan (2016) considered how an edugame-Minecraft Edu - could be used to develop competencies in the twenty-first century Australian high-school classroom. It was found that Minecraft Edu supported learners in problem-based learning and provided an opportunity for the development of SDL. In another study, Li and Zheng (2018) studied the relationship between SRL and self-efficacy of seventh grade students in a oneto-one computing environment (i.e. eSchoolbag), where self-efficacy was a significant predictor of SRL. Schweder and Raufelder (2021) also suggested that studies could further explore how SDL with technology foster youths' need of autonomy and competence as well as intrinsic and extrinsic motivation. Recently, Morris and Rohs (2021) conducted a literature review on how previous empirical studies facilitate SDL with technology during the formal education of children. Although it was found that the scaffolding of SDL and digital technologies is necessary for children, there has been rare research exploring such facilitation of SDL with technology. Given the wide repertoire of ICT tools that can be incorporated into teaching and learning, there continues to be a need to expand SDLT research, especially among the younger learners. 


\section{Collaborative learning with technology (CLT)}

In recent years, there has been growing interests in the effect of Collaborative Learning with Technologies (CLT) in facilitating social learning interactions and knowledge building in the Knowledge age society (Genlott \& Grönlund, 2016; Tan et al., 2017). Further, studies have found associations between ICT-enabled Collaborative learning tools with learner motivation, learning preferences, perceptions, and academic performances (Mansouri \& Piki, 2016; Martínez-Cerdá et al., 2018; Mora et al., 2020; Wu et al., 2017). A recent study (Shamir-Inbal \& Blau, 2021) has proposed an e-CSAMR framework, which analyze the levels of pedagogical changes during the integration of Collaborative learning in an online environment. This study suggested that the proposed e-CSAMR framework differs from other technology integrated pedagogical models in that it surpasses the junction between technological and pedagogical knowledge by further focusing on different levels of pedagogical change during technology integration. For example, through the e-CSAMR framework, students would first research on the topic and present the findings to their peers. Next, students would create the learning outcomes together and participate in online discussions. Students would further divide the tasks for each group members and modify towards the final outcomes together. Finally, students would develop learning process together so that the final learning outcome becomes a learning tool for other students. Another study (Er et al., 2021) also proposed a theoretical framework including three stages to engage students in dialogic collaborative peer feedback. The three stages consist of "planning and coordination of feedback", "discussion of feedback to support its uptake", and "translation of feedback into action" (Er et al., 2021, p. 172).

Studies on Collaborative Learning with Technology (CLT) reported mixed findings. In Mansouri and Piki's (2016) exploration of the usage of blogs among postgraduate business students, they found that the unique features of blogs support Collaborative Learning. However, some factors such as assessment strategies, group dynamics, and perception of time and effort required have been identified as potential barriers and challenges by the students. Additionally, they found that engagement level has significant association with achievements, but not with learning preferences. The study by Martínez-Cerdá et al. (2018) on university students demonstrated that ICT-supported pedagogical tools improve collaborative skills to different extents, and for different subjects. While tools like gamification, mixed reality, and social media had significant effect on the development of students' collaborative learning skills, other tools, such as open educational resources, personal webpages, file sharing, etc. were unable to do so. They also discussed that while ICT tools were useful in STEM (science, technology, engineering, and mathematics) subjects, only gamification has significant effect on non-STEM subjects.

Studies in Collaborative learning with Technology (CLT) continue to be dominant at the higher-education level and continuing education. In the meta-analysis by Manathunga and Hernández-Leo (2015), only 20.7\% of the articles identified addressed Collaborative learning with Technology (CLT) in K-12 schools. Some recent studies related to CLT at the elementary and high school levels are discussed below. Santos et al. (2018) reported that secondary students were highly motivated 
to use Web Geometry Laboratory, a web-based collaborative module, and improved on their mathematics achievements. In the study by Rodríguez et al. (2017), CLT brought both academic and non-academic advantages in an elementary-level interdisciplinary (language and literature, environmental science and artistic education) classroom. Students were able to utilise and share information, they reported to be more open to ideas from peers and to persevere in their learning goals. Other studies suggested that CLT increased awareness, understanding and collaboration among students, enhanced students' satisfaction in completing the learning activities and improved their academic performance (Roldán-Álvarez et al., 2020; Sabri et al., 2016). Given how ICT tools are constantly evolving and increasing in variety in response to learner needs (Mora et al., 2020; Wu et al., 2017), there is a need to continuously explore the possibilities to facilitate the development of Collaborative learning skills with the use of technologies in the K-12 setting.

\section{Validated instruments related to motivational strategies, self-directed learning and collaborative learning}

The Motivated Strategies for Learning Questionnaire (MSLQ) —a 81-item selfreport instrument—was created and has been extensively employed by researchers and practitioners to measure motivations and cognitions associated with the usage of learning strategies (Credé \& Phillips, 2011; Hilpert et al., 2013; Pintrich et al., 1991; Schunk, 2005). Multiple studies have adapted the MSLQ instrument to fit different user's needs (Pintrich et al., 1991). The MSLQ and its adapted versions have been validated internationally and across population types to be a reliable and useful measure of constructs for empirical research and practical applications (Credé \& Phillips, 2011; Duncan \& McKeachie, 2005). Much research, however, is still centered outside Asia-Pacific region.

Given the increasing prevalence of ICT in education and attention on developing twenty-first century skills, recent studies have attempted to modify the MSLQ with twenty-first century skills such as Self-directed Learning, Collaborative learning, or critical thinking. For example, Chai et al. (2016) modified the MSLQ into the Mobile-Assisted Seamless Chinese Learning Questionnaire (MSCLQ). The MSCLQ was proposed to measure motivation and the usage of learning strategies, specifically for the technology-enhanced seamless learning environments. In another study, Nold (2017) administered a modified MSLQ in college business courses which aimed to develop critical thinking skills.

The discussion above demonstrated that Information and Communication Technology (ICT) were integrated into the studies that measure students' motivation and perceptions of learning approaches in various versions of MSLQ. Choy et al. (2016) have thus modified the MSLQ and proposed a new model: Motivated Self-Directed Learning and Collaborative Learning (MSDLCL) model. The MSDLCL model aims to examine the relationship between motivation, learning approach with and without ICT. The MSDLCL model comprises seven sub-scales, they are: Task Value (TV), Self-Efficacy (SE) and Extrinsic Goal (EG), Self-directed Learning (SDL), Collaborative Learning (CL), Self-directed Learning with ICT (SDLT), and Collaborative 
Learning with ICT (CLT). This instrument will be adapted to address the research questions for the study.

\section{Research purpose}

A thorough review of literature showed that there is a lack of research investigating the integration of Information and Communication Technology (ICT) to develop Self-directed learning and Collaborate learning skills in Primary English writing lessons in the Asia-Pacific classrooms. Studies have shown that Primary school students experienced various challenges when developing their writing skills (Hogan et al., 2013). For example, traditional English Language writing program was mostly dominated by teacher-centered presentations with limited dialogue or information exchange with students, which was mostly because of teachers' aversion to risk and innovation. Moreover, the aim of such writing lessons is more on the preparation for high-stakes examinations, the instruction tends to be result-oriented rather than process-driven (Teo \& Kramer-Dahl, 2011).

This study aims to investigate students' perceived perceptions of about the Selfdirected learning and Collaborative learning experiences with and without the use of ICT tools in Primary Four English writing lessons in Singapore. There are two main research questions:

1. What are the students' perceptions on Self-directed learning (SDL) and Collaborative learning (CL) with and without technologies in English writing lessons? Are there any differences in the students' perceptions on Self-directed learning (SDL) and Collaborative learning (CL) when compared with SDL with Technology (SDLT) and CL with Technology (CLT) in English writing lessons?

2. Are there any differences in the students' perceptions on Self-directed learning (SDL) and Collaborative learning (CL) with and without technologies between the control group and the ICT-enhanced experimental group in English writing lessons?

\section{Methods}

To address the two proposed research questions, three government neighborhood Primary Schools in Singapore were invited to participate in the study. All three schools were located at the heartland/sub-urban areas of Singapore. In order to obtain consent from the participants and their parents/guardians, the purpose of the study and the involvement of the student participants were explained clearly at the beginning of the intervention to all students in class. Their parents/guardians received an information sheet from the research team that explained the study in detail. All student participants and their parents/guardian completed the consent forms prior to the data collection. A total of 408 Primary Four (Fourth Grade) students participated in the 5-week intervention voluntarily, with 214 students in the ICT-enhanced experimental group and 194 students in the control group. The 
details of the breakdown are shown in Table 1. To address potential internal validity issues, the strongest and the weakest classes in all three schools were not invited to participate in the study. All the participants were from mixed ability classes. In addition, all teacher participants attended one to two professional development sessions before the intervention to ensure that the five lessons for the control and the ICT-enhanced experimental groups were consistent. The lesson plans and respective teaching materials, such as pictures for writing, graphic organizers, etc. were all prepared, distributed and explained to the teacher participants. During the data collection process, at least one member of the research team was present in class to provide support and ensure that the intervention was implemented in a consistent manner.

\section{Intervention in the ICT-enhanced experimental group and the control group}

\section{Lesson One and Two: familiarization to planning, organizing, and writing} of the first narrative

The purpose of Lessons One and Two were to help the students to be familiarized with the process of writing narratives. During the first two lessons, all English teacher participants explained the three main stages in writing English narratives, namely: planning, organizing, and writing, to the students. Lesson One focused on planning and organizing the ideas and Lesson Two focused on narrative writing. Lesson One started with the planning stage, where students were first introduced to three pictures that were somewhat related (see Fig. 1). Teachers explained to the students that they could include two or three pictures in their writing. During the whole class discussion, teachers guided students to share some ideas on how to plan the narrative use a series of guiding questions. For example:

- When and where does the story take place? Why?

- What is the problem that the main character faced? Why?

- How does the problem resolve? Why?

At the end of the whole class discussion, most students had some ideas on how to plan their narratives. They started to decide on the main goals, the purposes, and the target audience of their narratives. In the organizing stage, students were asked to arrange their narratives into five steps: Orientation, Events,

Table 1 Number of participants in the control and the experimental groups in different schools

\begin{tabular}{lllr}
\hline Schools & Control Group & $\begin{array}{l}\text { ICT-enhanced experi- } \\
\text { mental Group }\end{array}$ & Total \\
\hline A & 107 (3 classes) & 104 (3 classes $)$ & 211 \\
B & $17(1$ class $)$ & 35 ( 2 classes $)$ & 52 \\
C & $70(3$ classes $)$ & 75 (2 classes $)$ & 145 \\
Total & 194 & 214 & 408 \\
\hline
\end{tabular}




\section{LESSON ONE (PLANNING)}

\section{Look at the pictures and get some ideas}
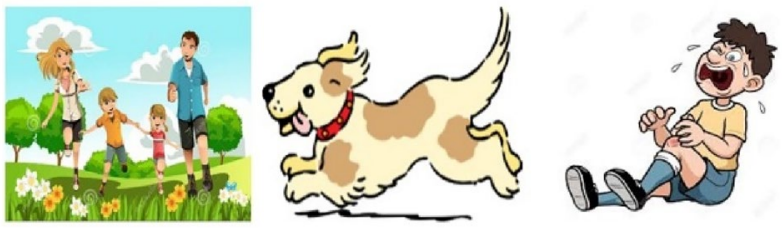

Fig. 1 Three pictures shown to Lesson One for narrative planning

Complication, Resolution and Ending in a graphic organizer. The teachers explained the five steps and guided the students to complete the organizing stages in Lesson One (see Fig. 2).

Lesson Two focused on the writing stage of narrative writing, where students were expected to complete their first narrative. Student developed the narratives based on their own ideas written in the graphic organizers in the previous lesson. They were also reminded by the teachers to refer to the pictures, the goals and the purpose of the narratives during the writing process. There were no differences in implementation of Lessons One and Two between the experiment and the control groups as students were getting familiarize with this narrative writing method of

\section{Planning to write}

\section{Model the process of planning using WWW WHAT2 HOW2 +WHY}

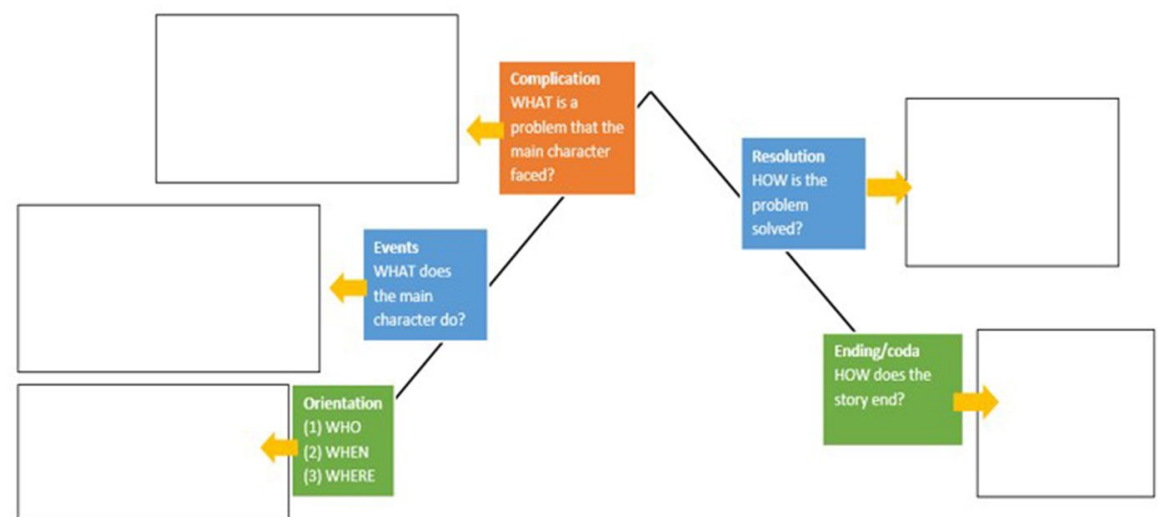

Fig. 2 Example of graphic organizer for organizing ideas 
using the pictures and the graphic organizer to plan, organize, and write their narrative.

\section{Lesson Three: organizing and writing first draft of narratives}

In this lesson, the students were given a new topic to write their narratives using the three stages of writing narratives that they learned from Lessons One and Two. As this was the second time that they used this writing technique, they were expected to complete all the planning, organizing and writing stages within one 60-min lesson. At the end of the lesson, the research team collected the hand-written narratives and processed them into word documents. The narratives were typed "as-is" with no editing. The typed narratives were uploaded to an online writing assistant, Grammarly, for suggestions to improve the quality of the narratives. A complete report was generated based on the narratives for each student to review in the next lesson.

There were some considerations during the implementation of this lesson. The students were not asked to type their narratives directly into a word processor because most of the teacher participants raised concerns that it could significantly slow down the writing process. The students were used to writing their narratives on paper. Hence, bringing a device into this lesson and ask the students to type their narrative may lead to unnecessary distractions such as difficulties in typing and other potential technical issues. As a result, the research team decided to use the traditional "paper-and-pen" method for the students to focus on writing the narratives.

During the data entry process, the research team carefully transferred the narratives into the word processor and ensured that all the grammatical, spelling, and other mistakes were captured. This was to allow the online writing assistant tool to identify the errors and provide appropriate recommendations to the students in the reports. The students in the control group completed the same writing activity. However, their narratives were not submitted to the online writing assistant tool for recommendations. The teacher participants marked the completed narratives and provided feedback to the students' work, which was similar to Lessons One and Two.

\section{Lesson Four: developing self-directed learning skills through reviewing the grammarly report and revising the narratives}

The objective for Lesson Four was to allow the students to review their reports from the online writing assistant tool and revise their narratives. In this lesson, students were expected to apply various self-directed learning skills, such as review, re-organize, and self-assess their narrative with the use of ICT tools. Before Lesson Four, all the online writing assistant reports were uploaded to the online notice board, Padlet, for ease of access by the students. Every student was given one tablet to access the online notice board and view the online writing assistant reports of their first drafts. The teachers from the ICT-enhanced experimental group provided guidelines to the students at the beginning of the lesson. First, students were reminded to review their overall goals and purpose of the narrative again during the revision. Second, students could choose to accept or reject the recommendations from the reports generated by the online writing assistant. If they felt that the recommendations were 
helpful, they could accept them. On the other hand, if they perceived that the recommendations were not applicable, student could reject the recommendations and revise according to their own way. After viewing the reports, they further revised their second drafts to improve the overall quality of the narratives.

In this lesson, the students in the ICT-enhanced experimental group viewed their reports, assess the quality of the recommendations, revised, and re-developed their narratives. Students could choose to make their revisions directly on the tablet and type their second draft online. Alternatively, they could choose to view their reports and write their second draft on paper. For those who did not complete all five steps (i.e.: Orientation, Events, Complication, Resolution and Ending) in the first drafts, they could continue to develop their narratives by referring to their ideas developed on the graphic organizer in the Lesson Three. At the end of Lesson Four, students were expected to complete their second drafts of the narratives and made it ready for peer review in Lesson Five. Students in the control group did not have access to the online writing assistant reports. However, they received written feedback from their teachers and made changes to their first drafts accordingly.

Lesson Five: developing collaborative learning skills through providing peer review comments on classmates' narratives and self-directed learning through further revision of narratives

The purpose for Lesson Five was to develop students' collaborative learning skills through the viewing and commenting their classmates' second drafts of the narratives. Student were grouped into groups of four for the peer reviewing activity and every student was given a device to access the group members' narratives on Padlet. Before they began the peer review process, their teachers provided clear instructions on the purpose of the peer review, what are their roles as reviewers and the three guiding questions that the students should answer during the review process. The guiding questions are:

1. What do you like the best about this narrative?

2. Are there any ideas in the narrative that are not clear? Please give examples.

3. Write down at least one suggestion you have on how the author could improve this narrative.

The students were asked post separate comments for each guiding question. As a result, one completed peer review should have three comments posts from the same reviewer, for Questions one, two and three, respectively. The teachers also reminded students to provide constructive feedback and follow the rules related to online etiquette. Every student was expected to review one to two narratives for their peers within their groups. At the end of the peer review, every student should receive at least three to six comments from their group members on Padlet. They used the comments provided by their peers to further revise their narratives. At the end of Lesson Five, they submitted the third and final version of the narratives. The control group student did not went 
through the online peer review process, they reviewed the paper copy of their group members' narratives and provide peer review comments in writing (Table 2).

\section{Data collection}

At the end of the 5-week intervention, all students from the ICT-enhanced experimental groups and the control groups were invited to complete the 28-item MSDLCL survey instrument voluntarily to measure their perceptions related to Self-directed learning (SDL) and Collaborative learning (CL) with and without ICT in Primary Four classes at three local Singapore schools. The data collected from the instrument helped to further investigate whether there were any significant differences between their perceptions towards Self-directed learning with and without ICT, and Collaborative learning with and without ICT for all groups (Research Question 2). In addition, further data analysis was done to compared if there were any significant differences in the perceptions between the ICT-enhanced experimental and the control groups. Data analysis and results will be discussed in the following section.

\section{Survey instrument}

The 28-item MSDLCL Questionnaire (Choy et al., 2016) was adopted for this study. The MSDLCL survey was derived from MSLQ (Pintrich et al., 1991). It was validated at the primary and the secondary levels by various studies (such as Choy et al., 2016; Duncan \& McKeachie, 2005). There are seven sub-scales in the questionnaire, they are: Task Value (TV), Self-Efficacy (SE), Extrinsic Goal (EG), Self-directed learning (SDL), Self-direct learning with technologies (SDLT), Collaborative learning (CL), and Collaborative learning with technologies (CLT). Some examples of the survey items in each sub-scale are provided in Table 3.

Within the seven sub-scales, the first three constructs, namely Task Value (TV), Self-Efficacy (SE), Extrinsic Goal (EG), are related to a higher-order factor labelled as motivation. The Self-directed learning (SDL), Self-direct learning with technologies (SDLT), Collaborative learning (CL), and Collaborative learning with technologies (CLT) are under another higher-order factor called Learning Approach. This instrument has been validated for Primary and Secondary school students.

As this study was predominantly designed as a quantitative study, only some qualitative data was collected from the participants. The different versions of narratives, the online writing assistant reports, and the comments from the online notice boards from all five lessons were collected for simple post-hoc analysis. The qualitative data was collected to substantiate the results from the quantitative data analysis. 


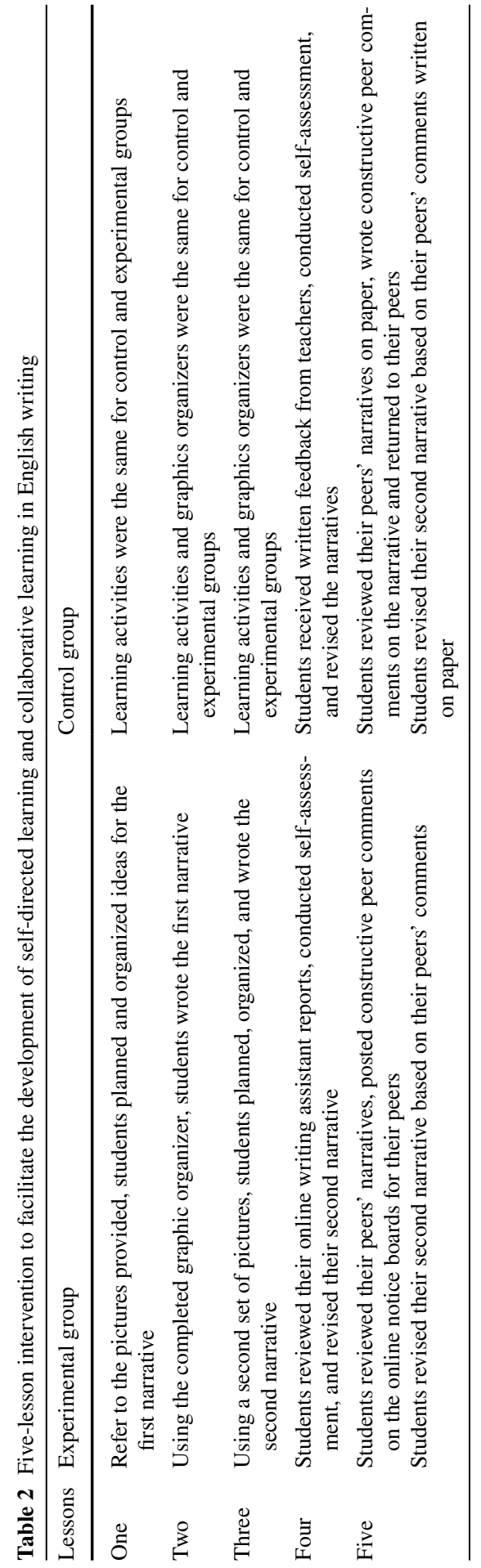


Table 3 Sample items from the MSDLCL survey

\begin{tabular}{|c|c|}
\hline Sub-scales & Sample items for each sub-scale \\
\hline Task value (TV) & $\begin{array}{l}\text { I spend a lot of my free time finding out more about interesting } \\
\text { topics which have been discussed in class }\end{array}$ \\
\hline Self-efficacy (SE) & $\begin{array}{l}\text { I am confident I can learn the topics taught in this class } \\
\text { I am confident I will do well in this class }\end{array}$ \\
\hline Extrinsic goal (EG) & $\begin{array}{l}\text { I want to do well in this class because it is important to show } \\
\text { my ability to my family, friends, or others }\end{array}$ \\
\hline Self-directed learning (SDL) & $\begin{array}{l}\text { In this class, I set goals for my study } \\
\text { In this class, I try to check my progress when I study }\end{array}$ \\
\hline Self-directed learning with ICT (SDLT) & $\begin{array}{l}\text { In this class, I use the computer to organize and save the infor- } \\
\text { mation for my learning }\end{array}$ \\
\hline Collaborative learning (CL) & $\begin{array}{l}\text { In this class, my classmates and I actively work together to } \\
\text { learn new things }\end{array}$ \\
\hline Collaborative learning with ICT (CLT) & $\begin{array}{l}\text { In this class, my classmates and I actively share ideas in the } \\
\text { online platforms } \\
\text { In this class, my classmates and I actively discuss our ideas } \\
\text { online to make our work better }\end{array}$ \\
\hline
\end{tabular}

\section{Data analysis and results}

The purpose of this study was to find out the students' perceived perceptions of about their Self-directed learning (SDL) and Collaborative learning (CL) experiences with and without the use of ICT tools in Primary Four English writing classes in Singapore. Using mainly quantitative data collection and analysis, the study aimed to investigate students' perceptions of Self-directed learning (SDL) and Collaborative learning (CL) experiences when they were writing narratives in Primary Four English classes. Furthermore, with the use of ICT tools, such as online writing assistant tools to promote Self-directed learning and online notice board for peer reviews to promote Collaborative learning, are there any significant differences in the students' perceptions in Self-directed learning (SDL) and Collaborative learning (CL) with and without the use of technology? In the following sections, the two research questions posed in this study will be discussed.

Research Question 1 Differences in students' perceptions on Self-directed learning (SDL) and Collaborative learning (CL) when compared with Self-directed learning with technologies (SDLT) and Collaborative learning with technologies (CLT) in English writing lessons.

Descriptive statistics were employed to analyze the overall distribution of data. A total of 408 participants completed the MSDLCL questionnaire at the end of study, there were 202 participants from the control group and 206 participants from the experimental group. This study is a quasi-experimental design as the research team adopted existing class structure and randomly assigned classes into the control groups and the ICT-enhanced experimental groups. 
Table 4 The means, standard deviations and pairwise comparisons for SDL, SDLT, CL and CLT for all participants $(p$-value $<.01 * *)$

\begin{tabular}{lllc}
\hline Sub-scales & Overall $(N=408)$ & $\begin{array}{l}\text { Cronbach's } \\
\text { alpha }\end{array}$ & $t$ \\
\hline Self-directed learning (SDL) & $3.87(.576)$ & .78 & $9.61^{* * *}$ \\
Self-directed learning with technology (SDLT) & $3.40(.982)$ & .85 & $9.35^{* * *}$ \\
Collaborative learning (CL) & $3.80(.859)$ & .84 & .83 \\
Collaborative learning with technology (CLT) & $3.35(1.040)$ & & \\
\hline
\end{tabular}

Table 5 The means and standard deviations for SDL, SDLT, CL and CLT for control and experimental groups

\begin{tabular}{lll}
\hline Sub-scales & Control $(N=194)$ & Experiment $(N=214)$ \\
\hline Self-directed learning (SDL) & $3.82(.526)$ & $3.90(.618)$ \\
Self-directed learning with technology (SDLT) & $3.21(.895)$ & $3.58(1.032)$ \\
Collaborative learning (CL) & $3.73(.895)$ & $3.86(.819)$ \\
Collaborative learning with technology (CLT) & $2.98(1.009)$ & $3.72(.935)$ \\
\hline
\end{tabular}

Overall, the participants showed slightly positive perceptions towards all four subscales in the English writing lessons. The means for Self-directed learning (SDL) for all groups was $3.78(\mathrm{SD}=.576)$ out of a five-point Likert scale. The means for Collaborative learning $(\mathrm{CL})$ for all groups was $3.80(\mathrm{SD}=.859)$. The means for SDLT was $3.40(\mathrm{SD}=.982)$ and for $\mathrm{CL}$ was $3.35(\mathrm{SD}=1.040)$ (see Table 4). The Cronbach's alpha levels for all four sub-scales ranged from 0.78 to 0.85 , which indicated the internal consistency for the sub-scales were acceptable.

Further investigation of the means of the four sub-scales showed that selfdirected learning with technology (SDLT) and Collaborative learning with technology (CLT) were consistently lower than the means of self-directed learning (SDL) and Collaborative learning (CL) in all groups. Paired sample $t$-tests were employed to analyze whether there were any significant differences. The results showed that there were significant differences when comparing SDL (3.87) with SDLT (3.40) $(t=9.61 ; p$-value $>.01)$ and when comparing CL (3.80) with CLT (3.35) $(t=9.35$; $p$-value $>.01)($ See Table 3$)$.

Research Question 2 Differences in the students' perceptions of SDL when compared with SDLT, CL when compared with CLT between the control and the ICT-enhanced experimental groups.

Research question two focused on the comparisons of the four sub-scales between the control group and the ICT-enhanced experimental group. The means for Selfdirected learning (SDL) for the control and the experimental groups were 3.82 $(\mathrm{SD}=.526)$ and $3.90(\mathrm{SD}=.618)$ respectively. The means for Self-directed learning with technology was consistently lower than SDL, they are $3.21(\mathrm{SD}=.895)$ for the control group and $3.58(\mathrm{SD}=1.032)$ for the experimental group (see Table 5). 
The means of Collaborative learning (CL) for the control group was 3.73 $(\mathrm{SD}=.895)$ and for the experimental group as $3.86(\mathrm{SD}=.819)$. In Collaborative learning with technology, the means for the control group was $2.98(\mathrm{SD}=1.009)$ and the experimental group was $3.72(\mathrm{SD}=.935)$, both means were consistently lower than CL.

The means and standard deviations of the control and the ICT-enhanced experimental groups showed that there were some differences in the students' perceptions of self-directed learning (SDL), self-directed learning with ICT (SDLT), Collaborative learning (CL), and Collaborative learning with ICT (CLT). Further statistical analysis was conducted find out whether there were any significant differences between the two groups.

As the students were grouped in pre-assigned ability classes, one-way MANCOVA was conducted to increase the ability to detect differences between the control and the ICT-enhanced experimental groups. In MSDLCL questionnaire, motivational level comprised three sub-scales: Task Value (TV), Self-Efficacy (SE), and Extrinsic Goal (EG). These items in the MSDLCL questionnaire provided data on the students' perceptions of their motivation. Following one-way MANCOVA, posthoc pairwise comparisons were used to further analyze the differences between the control and the experimental groups in SDL. SDLT, CL and CLT factors. The data was analyzed first using MANCOVA to avoid potential Type I errors due to multiple t-test comparisons being conducted using the data set. As the research team was unable to obtain data related to the students' academic performances before the intervention, the motivational level of the students was used to serve as the covariate of the study. Previous studies have shown consistent findings where motivation level was highly correlated to academic achievements (Broussard \& Garrison, 2009; Nauzeer \& Jaunky, 2021).

One-way MANCOVA showed that there were significant differences in the students' perceptions in SDL, SDLT, CL, and CLT between the control and the experimental groups (Wilks' Lambda $=14.93$, $p$-value $<0.01$ ). Pairwise comparisons showed that there are significant differences in the factors related to the use of technologies. Collaborative learning with technology (CLT) showed the largest difference in students' perceptions, where the adjusted means for the control group was 3.03 and the experimental group was 3.67 ( $p$-value $<0.01$ ). Self-directed learning with technologies (SDLT) also showed significant differences between the two groups. The adjusted means for the control group was 3.27 and for the experimental group was 3.53 ( $p$-value $<0.01)$ (see Table 6). There are no significant differences between the control and the experimental groups for self-directed learning (SDL) and Collaborative learning (CL) in their English writing lessons.

During the data analysis process, some narratives were examined to substantiate the quantitative findings. The research team observed that students did not merely followed the recommendations from the online writing assistant reports and made changes to their narratives. They were able to read the recommendations from the reports, raise questions about the quality of the recommendations with their teachers and peers, and decide to revise their narratives in other more creative ways. During Lesson Four. some students also noticed that they should not follow all the recommendations from the reports as they may not be applicable to their narratives. One 
Table 6 Pairwise comparisons of SDL, CL, SDLT \& CLT between the control and the experimental groups $(p$-value $<0.01 * *)$

\begin{tabular}{lll}
\hline Sub-scales & $\begin{array}{l}\text { Control group adjusted } \\
\text { means }(N=194)\end{array}$ & $\begin{array}{l}\text { Experiment group } \\
\text { adjusted means } \\
(N=214)\end{array}$ \\
\hline Self-directed learning (SDL) & 3.86 & 3.87 \\
Self-directed learning with technology (SDLT) & $3.27 * *$ & $3.53^{* *}$ \\
Collaborative learning (CL) & 3.79 & 3.80 \\
Collaborative learning with technology (CLT) & $3.03 * *$ & $3.67 * *$ \\
\hline
\end{tabular}

common example observed was that the reports suggested US English rather than UK English. Many students were able to point out that their use of words such as "colours" or "centre" were correct, but the words were marked as spelling errors in the reports. It was observed that students ignored these errors and kept their words. These students demonstrated that they were using self-directed learning skills as assess their own work and utilized the online writing assistant reports merely as a tool to facilitate their revisions.

During Lesson Five, students used the tablets and the online notice boards to provide comments to their peers' narratives. At the beginning, some peer comments were short and generic, the students did not follow the guiding questions. However, once the teachers reminded the students about the guiding questions, students started to follow the structured of the guiding questions. The quality of the online comments was longer, more specific, and more constructive towards the end of the posting.

\section{Discussions}

The purpose of this study was to investigate the Primary Four students' perceptions of Self-directed learning and Collaborative learning with and without ICT in their English writing lessons in Singapore. The first key finding of the study showed that students perceptions of Self-directed learning (SDL) and Collaborative learning (CL) were significantly higher than their perceptions of Self-directed learning with technology (SDLT) and Collaborative learning with technology (CLT) respectively. This result suggested that students perceived they have less opportunities to apply and develop self-directed learning and collaborative learning skills with the use of technology in learning. As Singapore teachers embarked on the new EdTech Plan for the next decade, they are expected to be facilitators of meaningful tech-mediated learning experiences, to guide the students become future-ready digital learners (Ministry of Education Singapore, 2021a). As the findings showed that students perceived to have developed more positive attitudes towards SDL and CL, teachers could gradually design more self-directed learning and collaborative learning activities with the use of technologies to promote the development of SDLT and CLT. This echoed the findings from previous studies that teachers should develop 
students' learning processes by engaging them in ICT-enhanced learning environment (Lee et al., 2014).

The second key finding of the study showed that students' perceptions of Selfdirected learning with technology (SDLT) in the ICT-enhanced experimental group were significantly higher than the control group. The results suggested that students in the experimental group perceived that they were able to get more ideas on how to set their own goals for the narrative writing, how to plan and organize ideas, and how to improve their work with the use of online writing assistant tools, online notice boards and tablets. As the students received their feedback from the online tools, they were actively engaged in reading through the recommendations from the online writing assistant reports.

The third key finding of the study showed that there were significant differences in the students' perceptions of Collaborative learning with ICT (CLT) between the control and the experimental groups, where the experimental groups perceived more positively that they were able to share ideas with their peers on the online notice boards and comment on each other's work. Further research could focus on how to facilitate students to provide quality constructive feedback to their peers and how students could make use of the peer comments to further improve the overall quality of their narratives.

In this study, we used the students' motivational level as the covariate of the study, it would be ideal if future research studies could have access to the students' academic performance and use it as the covariate of this study. This would ensure that students' differences in their performances are directly being addressed.

\section{Applications of the intervention to blended learning or online learning environments}

Although the data was collected before the Covid-19 pandemic and students were using ICT tools in face-to-face learning environment, the learning activities designed in this study could be applied to blended learning and online learning settings with just minor adjustments. In Home-based Learning or online learning environment, Lessons One and Two could be conducted as synchronous online learning lessons where teachers provide instructions and guidance through online meeting platforms such as Zoom. Students could submit their first drafts through learning management systems, such as Google classroom or BlackBoard. One of the advantages for online learning is that students could be given more time to complete their first drafts before submission. The online submission of drafts would make the submission of first drafts to online writing assistant tool easier for the teachers, as the teachers do not need to spend time processing the written drafts into word documents. Once the writing assistant reports are ready, teachers could upload the reports on the online notice boards and allow students to complete Lesson Four within a designated time frame as asynchronous online learning activity. Students could access their online writing assistant reports, revise their first drafts, and post the second drafts on the notice boards. Teachers could utilize the notice boards as one of the communication platforms to monitor students' progress. With the use of the online notice boards, 
students could provide constructive feedback to their peers anytime and anywhere. Re-designing the intervention from this study could potentially provide more benefits to the teachers and the students. First, students could be given more time to work on the various tasks, such as planning, organizing, and writing the narratives, revising the drafts and providing constructive peer feedback. Second, teachers could facilitate the students learning progress on various online platforms, they could also provide simple differentiated instructions to students who may need various levels of support and scaffold during the writing process.

Potential challenges for conducting this lesson in blended or online learning environment could be that students are not as motivated to complete the tasks in an asynchronous online learning environment. There may be potential classroom management issues as teachers need to monitor the online notice boards closely to ensure that students follow the rules and provide constructive feedback to their peers. In a blended or online learning environment, teachers may need to provide additional instructions to the students and the parents so that the lessons could be carried out smoothly.

\section{Conclusion}

To prepare our students to become future-ready digital learners and citizens in the knowledge society, self-directed learning and collaborative learning are some of the key 21st-century skills and competencies that the students need to develop in their learning (Ministry of Education Singapore, 2021a; Voogt \& Pareja Roblin, 2010). The purpose of this study is to find out students' perceptions of Self-directed learning (SDL) and Collaborative learning (CL) with and without the use of ICT in English writing classes in Singapore. The results showed that Primary Four students' perceptions for Self-directed learning (SDL) and Collaborative learning (CL) were quite positive in both control and experimental groups. However, their perceptions for Self-directed learning with technologies (SDLT) and Collaborative learning with technologies (CLT) were consistent lower than without ICT. MANCOVA results showed that there were significant differences between the control and the experimental groups in the perceptions of Self-directed learning with technologies (SDLT) and Collaborative learning with technologies (CLT). The students in the ICT-enhanced experimental group, who experienced the use of tablets, online writing assistant tool and online notice boards showed significantly more positive attitudes towards both Self-directed learning (SDL) and Collaborative learning (CL) with technology.

Future studies could investigate students' perceptions towards SDL and CL with technology being infused into blended learning or online learning experience. With the uncertainties of the Covid-19 situation, educators could seek this opportunity to design more meaningful ICT-enhanced learning experiences for the students.

Funding This study was funded by Singapore Ministry of Education (MOE) under the Education Research Funding Programme (OER 09/17 CYL) and administered by National Institute of Education 
(NIE), Nanyang Technological University, Singapore. Any opinions, findings, and conclusions or recommendations expressed in this material are those of the author(s) and do not necessarily reflect the views of the Singapore MOE and NIE.

\section{Declarations}

Conflict of interest The authors declare no conflict of interest.

Ethical approval The IRB was approved with reference number IRB-2017-10-010 by the Institutional Review Board at Nanyang Technological University.

Consent to participate All participants and their parents/guardians were informed about the study and submitted their signed consent before the data was collected and analyzed for this manuscript.

Consent for publication The authors give consent to Journal of Computers in Education to publish this manuscript if it is being accepted.

\section{References}

Anderson, R. (2008). Implications of the information and knowledge society for education. Springer.

Bai, B. (2018). Understanding primary school students' use of self-regulated writing strategies through think-aloud protocols. System, 78, 15-26. https://doi.org/10.1016/j.system.2018.07.003

Barkley, E. F., Cross, K. P., \& Major, C. H. (2014). Collaborative learning techniques: A handbook for college faculty. Wiley.

Brockett, R. G. (2000). Is it time to move on? Reflections on a research agenda for self-directed learning in the 21st century. Paper presented at the TITLE AERC 2000: An International Conference. Proceedings of the Annual Adult Education Research Conference (Vancouver).

Broussard, S. C., \& Garrison, M. E. B. (2009). The relationship between classroom motivation and academic achievement in elementary-school-aged children. Family and Consumer Sciences, 33(2), 106-120. https://doi.org/10.1177/1077727X04269573

Callaghan, N. (2016). Investigating the role of Minecraft in educational learning environments. Educational Media International, 53(4), 244-260.

Chai, C. S., Wong, L. H., \& King, R. B. (2016). Surveying and modeling students' motivation and learning strategies for mobile-assisted seamless Chinese language learning. Journal of Educational Technology \& Society, 19(3), 170-180.

Choy, D., Feng, D., Chai, C. S., Koh, H. L. J., \& Tsai, P-S. (2016). Singapore primary and secondary students' motivated approaches for learning: A validation study.

Cohen, J. D., Renken, M., \& Calandra, B. (2017). Urban middle school students, twenty-first century skills, and STEM-ICT careers: Selected findings from a front-end analysis. TechTrends, 61(4), 380-385.

Credé, M., \& Phillips, L. A. (2011). A meta-analytic review of the motivated strategies for learning questionnaire. Learning and Individual Differences, 21(4), 337-346.

Dillenbourg, P. (1999). What do you mean by collaborative learning? In P. Dillenbourg (Ed.), Collaborative-learning: Cognitive and computational approaches (pp. 1-19). Elsevier.

Duncan, T. G., \& McKeachie, W. J. (2005). The making of the motivated strategies for learning questionnaire. Educational Psychologist, 40(2), 117-128.

Er, E., Dimitriadis, Y., \& Gašević, D. (2021). Collaborative peer feedback and learning analytics: Theoryoriented design for supporting class-wide interventions. Assessment \& Evaluation in Higher Education. https://doi.org/10.1080/02602938.2020.1764490

Genlott, A. A., \& Grönlund, $\AA$. (2016). Closing the gaps-Improving literacy and mathematics by ictenhanced collaboration. Computers \& Education, 99, 68-80.

Goh, D., \& Kale, U. (2016). The urban-rural gap: Project-based learning with Web 2.0 among West Virginian teachers. Technology, Pedagogy and Education, 25(3), 355-376. 
Hilpert, J. C., Stempien, J., van der Hoeven Kraft, K. J., \& Husman, J. (2013). Evidence for the latent factor structure of the MSLQ: A new conceptualization of an established questionnaire. SAGE Open, 3(4), 2158244013510305.

Hogan, D., Towndrow, P., Kwek, D., Chan, M., \& Rahim, R. A. (2013). CRPP Core 2 research program: Core 2 interim final report. National Institute of Education.

Hong, H.-Y., \& Chai, C. S. (2017). Principle-based design: Development of adaptive mathematics teaching practices and beliefs in a knowledge building environment. Computers \& Education, 115, 38-55.

Jossberger, H., Brand-Gruwel, S., Boshuizen, H., \& Van de Wiel, M. (2010). The challenge of selfdirected and self-regulated learning in vocational education: A theoretical analysis and synthesis of requirements. Journal of Vocational Education and Training, 62(4), 415-440.

Karatas, K., \& Arpaci, I. (2021). The role of self-directed learning, metacognition, and 21st century skills predicting the readiness for online learning. Contemporary Educational Technology, 13(3), 300. https://doi.org/10.30935/cedtech/10786

Kicken, W., Brand-Gruwel, S., Van Merriënboer, J., \& Slot, W. (2009). Design and evaluation of a development portfolio: How to improve students' self-directed learning skills. Instructional Science, 37(5), 453-473.

Lawlor, J., Marshall, K., \& Tangney, B. (2016). Bridge21-exploring the potential to foster intrinsic student motivation through a team-based, technology-mediated learning model. Technology, Pedagogy and Education, 25(2), 187-206.

Lee, E., \& Hannafin, M. J. (2016). A design framework for enhancing engagement in student-centered learning: Own it, learn it, and share it. Educational Techonology Research and Development, 64, 707-734. https://doi.org/10.1007/s11423-015-9422-5

Lee, K., Tsai, P.-S., Chai, C. S., \& Koh, J. H. L. (2014). Students perceptions of self-directed learning and collaborative learning with and without technology. Journal of Computer Assisted Learning, 30(5), 425-437. https://doi.org/10.1111/jcal.12055

Leong, W. S., Ismail, H., Costa, J. S., \& Tan, H. B. (2018). Assessment for learning research in East Asian countries. Studies in Educational Evaluation, 59, 270-277.

Li, S., \& Zheng, J. (2018). The relationship between self-efficacy and self-regulated learning in oneto-one computing environment: The mediated role of task values. The Asia-Pacific Education Researcher, 27(6), 455-463.

Long, H. B. (1994). Resources related to overcoming resistance to self-direction in learning. New Directions for Adult and Continuing Education, 1994(64), 13-21.

Loyens, S. M., Magda, J., \& Rikers, R. M. (2008). Self-directed learning in problem-based learning and its relationships with self-regulated learning. Educational Psychology Review, 20(4), 411-427.

Manathunga, K., \& Hernández-Leo, D. (2015). Has research on collaborative learning technologies addressed massiveness? A literature review. Educational Technology \& Society, 18(4), 357-370.

Mansouri, S. A., \& Piki, A. (2016). An exploration into the impact of blogs on students' learning: Case studies in postgraduate business education. Innovations in Education and Teaching International, 53(3), 260-273.

Martínez-Cerdá, J.-F., Torrent-Sellens, J., \& González-González, I. (2018). Promoting collaborative skills in online university: Comparing effects of games, mixed reality, social media, and other tools for ICT-supported pedagogical practices. Behaviour \& Information Technology, 37(10-11), 1055-1071.

Ministry of Education, Singapore. (2021a). Educational technology plan. Retrieved January 2022 from https://www.moe.gov.sg/education-in-sg/educational-technology-journey/edtech-plan

Ministry of Education, Singapore. (2021b). 21st century competencies. Retrieved January 2022 from https://www.moe.gov.sg/education-in-sg/21st-century-competencies

Mora, H., Signes-Pont, M. T., Fuster-Guilló, A., \& Pertegal-Felices, M. L. (2020). A collaborative working model for enhancing the learning process of science \& engineering students. Computers in Human Behavior, 103, 140-150.

Morris, T. H., \& Rohs, M. (2021). The potential for digital technology to support self-directed learning in formal education of children: A scoping review. Interactive Learning Environments. https://doi.org/ $10.1080 / 10494820.2020 .1870501$

Morrison, D., \& McCutheon, J. (2019). Empowering older adults' informal, self-directed learning: Harnessing the potential of online personal learning networks. Research and Practice in Technology Enhanced Learning, 14(1), 10. 
Nauzeer, S., \& Jaunky, V. C. (2021). A meta-analysis of the combined effetcs of motivation, learning and personality traits on academic performance. Pedagogical Research, 6(3), 0097. https://doi.org/10. 29333/pr/10963

Naz, S., \& Hussain, M. A. (2020). Trends in self directed learning: Constraints and opportunities. Journal of Educational Sciences, 7(1), 63-75.

Nold, H. (2017). Using critical thinking teaching methods to increase student success: An action research project. International Journal of Teaching \& Learning in Higher Education, 29, 17-32.

Pintrich, P. R. (2004). A conceptual framework for assessing motivation and self-regulated learning in college students. Educational Psychology Review, 16, 385-407. https://doi.org/10.1007/ s10648-004-0006-X

Pintrich, P. R., Smith, D. A. F., Garcia, T., \& McKeachie, W. J. (1991). A manual for the use of the motivated strategies for learning questionnaire $(M S L Q)$. University of Michigan, National Center for Research to Improve Postsecondary Teaching and Learning.

Robertson, J. (2011). The educational affordances of blogs for self-directed learning. Computers \& Education, 57(2), 1628-1644.

Rodríguez, A. I., Riaza, B. G., \& Gómez, M. C. S. (2017). Collaborative learning and mobile devices: An educational experience in primary education. Computers in Human Behavior, 72, 664-677.

Roldán-Álvarez, D., Bacelo, A., Martín, E., \& Haya, P. A. (2020). Impact of different interaction protocols on group communication, satisfaction and learning outcomes of primary school children when using multitouch tabletops. Computers \& Education, 152, 103875.

Sabri, M., Khalid, F. K., \& Li, L. K. (2016). Assessing students engagement in an online student question-generation activity towards their learning motivation. International Journal of Languages, Literature and Linguistics, 2(1), 23-31.

Sahlin, J. S., Tsertsidis, A., \& Islam, M. S. (2017). Usages and impacts of the integration of information and communication technologies (ICTs) in elementary classrooms: Case study of Swedish municipality schools. Interactive Learning Environments, 25(5), 561-579.

Saks, K., \& Leijen, Ä. (2014). Distinguishing self-directed and self-regulated learning and measuring them in the e-learning context. Procedia-Social and Behavioral Sciences, 112, 190-198.

Salonen, A., Hartikainen-Ahia, A., Hense, J., Scheersoi, A., \& Keinonen, T. (2017). Secondary school students' perceptions of working life skills in science-related careers. International Journal of Science Education, 39(10), 1339-1352.

Santos, V., Quaresma, P., Marić, M., \& Campos, H. (2018). Web geometry laboratory: Case studies in Portugal and Serbia. Interactive Learning Environments, 26(1), 3-21.

Schunk, D. H. (2005). Self-regulated learning: The educational legacy of Paul R. Pintrich. Educational Psychologist, 40(2), 85-94. https://doi.org/10.1080/00220671.2021.1887066

Schweder, S., \& Raufelder, D. (2021). Interest and learning strategies. The moderating function of flow in different learning contexts. The Journal of Education Research. https://doi.org/10.1080/00220671. 2021.1887066

Shah, R., \& Quinn, M. (2016). Mind the gap: Global quality norms, national policy interpretations and local praxis in Timor-Leste. Compare: A Journal of Comparative and International Education, 46(3), 394-413.

Shamir-Inbal, T., \& Blau, I. (2021). Characteristics of pedagogical change in integrating digital collaborative learning and their sustainability in a school culture: e-CSAMR framework. Journal of Computer Assisted Learning, 37(3), 825-838. https://doi.org/10.1111/jcal.12526

Shih, H. J. (2021). The use of individual and collaborative learning logs and their impact on the development of learner autonomy in the EFL classroom in Taiwan. Innovation in Language Learning and Teaching, 15(3), 195-209. https://doi.org/10.1080/17501229.2020.1737703

Siddiq, F., Gochyyev, P., \& Wilson, M. (2017). Learning in digital networks-ICT literacy: A novel assessment of students' 21st century skills. Computers \& Education, 109, 11-37.

Sletten, S. R. (2017). Investigating flipped learning: Student self-regulated learning, perceptions, and achievement in an introductory biology course. Journal of Science Education and Technology, 26, 347-358. https://doi.org/10.1007/s10956-016-9683-8

Stahl, G., Koschmann, T., \& Suthers, D. (2014). Computer-supported collaborative learning. In R. Sawyer (Ed.), The Cambridge handbook of the learning sciences (2nd ed.). Cambridge University Press.

Tan, S. C., Cheah, H. M., Chen, W., \& Choy, D. (2017). Pushing the frontier: A cohesive system-wide approach to integrating ICT into education. Springer.

Teo, P., \& Kramer-Dahl, A. (2011). Of monsters and mayhem: Teaching suspense stories in a Singapore classroom. Journal of Writing Research, 3(1), 19-49. 
Trúchly, P., Medvecký, M., Podhradský, P., \& El Mawas, N. (2019). STEM education supported by virtual laboratory incorporated in self-directed learning process. Journal of Electrical Engineering, 70(4), 332-344.

UNESCO. (2005). Towards knowledge societies: UNESCO world report. UNESCO.

UNESCO. (2017). Leveraging information and communication technology to achieve Education 2030: Report of the UNESCO 2017 International Forum on ICT and Education 2030, 10-11 July 2017, Qingdao, the People's Republic of China. Paper presented at the UNESCO International Forum on ICT and Education 2030, Qingdao China, 2017, Qingdao, China.

Van de Oudeweetering, K., \& Voogt, J. (2018). Teachers' conceptualization and enactment of twentyfirst century competences: Exploring dimensions for new curricula. The Curriculum Journal, 29(1), $116-133$.

Voogt, J., \& Pareja Roblin, N. (2010). 21st century skills discussion paper. University of Twente.

Wu, Y.-C.J., Pan, C.-I., \& Yuan, C.-H. (2017). Attitudes towards the use of information and communication technology in management education. Behaviour \& Information Technology, 36(3), 243-254.

Yamada, M., Goda, Y., Matsuda, T., Kato, H., \& Miyagawa, H. (2015). The relationship among selfregulated learning, procrastination, and learning behaviors in blended learning environment. International Association for Development of the Information Society.

Yang, D.-C., \& Li, M.-N. (2013). Assessment of animated self-directed learning activities modules for children's number sense development. Journal of Educational Technology \& Society, 16(3), 44-58.

Zimmerman, B. J., \& Schunk, D. H. (2008). Motivation: An essential dimension of self-regulated learning. In B. J. Zimmerman \& D. H. Schunk (Eds.), Motivation and self-regulated learning: Theory, research, and applications (pp. 1-30). Lawrence Erlbaum.

Publisher's Note Springer Nature remains neutral with regard to jurisdictional claims in published maps and institutional affiliations.

Doris Choy is an Associate Professor in the Learning Sciences and Assessment Academic Group, National Institute of Education, Nanyang Technological University. Her research interests include technology-enhanced learning, technological pedagogical content knowledge, teacher education, adult learning and instructional design. Her research projects include the development of students' twenty-first century skills in technology-enhanced learning environments, beginning teachers development of pedagogical knowledge and skills in teaching and learning, and use of personal device for learning in online and blended learning environment (Corresponding author: doris.choy@nie.edu.sg).

Yin Ling Cheung is an Associate Professor in English Language \& Literature Academic Group and Associate Dean, Outreach and Engagement, at the Office of Graduate Studies and Professional Learning, National Institute of Education, Nanyang Technological University. She is an applied linguist who specializes in academic writing and writing instruction. Her unique contribution to academic writing and writing instruction is the development of a socio-cognitive and motivation-and-learning (SCML) model to teaching writing, whose novelty is to help students improve their writing by focusing on the rhetorical goal and thinking processes embedded in academic writing, assisted by ICT integrated into the pedagogy. Her research has been funded by the NIE Academic Research Fund, the MOE Education Research Funding Programme, and the Singapore Millennium Foundation. 